DECOLONIZING ETHNOGRAPHY 
This page intentionally left blank 


\section{DECOLONIZING ETHNOGRAPHY}

Undocumented Immigrants and New Directions in Social Science 
(c) 2019 DUKE UNIVERSITY PRESS All rights reserved Printed in the United States of America on acid-free paper $\infty$ Designed by Courtney Leigh Baker Typeset in Minion Pro and Avenir by CGI

Library of Congress Cataloging-in-Publication Data Names: Alonso Bejarano, Carolina, [date] author. | López Juárez, Lucia, author. | Mijangos García, Mirian A., author. | Goldstein, Daniel M., [date] author.

Title: Decolonizing ethnography : undocumented immigrants and new directions in social science / Carolina Alonso Bejarano, Lucia López Juárez, Mirian A. Mijangos García, and Daniel M. Goldstein.

Description: Durham : Duke University Press, 2019. | Includes bibliographical references and index.

Identifiers: LCCN 2018042313 (print) | LCCN 2018060919 (ebook) ISBN 9781478004547 (ebook) ISBN 9781478003625 (hardcover : alk. paper) ISBN 9781478003953 (pbk. : alk. paper)

Subjects: LCSH: Anthropology-Methodology. | Ethnology-Methodology. |

Eurocentrism. | Critical pedagogy. | Racism in higher education. |

Education, Higher-Social aspects. | Education and globalization. |

Decolonization. | Marginality, Social-Developing countries.

Classification: LCC LC191.98.D44 (ebook) |

LCC LC191.98.D44 A46 2019 (print) DDC 378.008-dc23

LC record available at https://lccn.loc.gov/2018042313

Cover art: Illustration and hand lettering by Peter Quach. Courtesy of the artist.

(opposite): Figure FM.1. Photo by Daniel M. Goldstein. 
Para nuestro querido Evandro, Q.E.P.D.

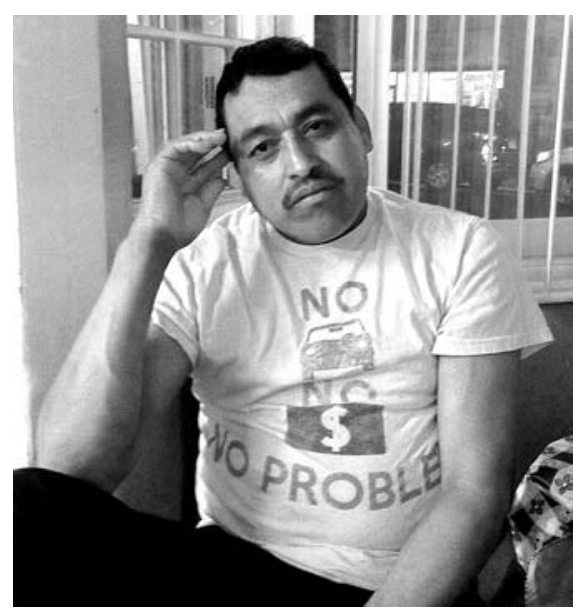


This page intentionally left blank 